\title{
COVID-19 vaccine-readiness for ocrelizumab and other anti-CD20-depleting therapies in multiple sclerosis and other autoimmune diseases
}

\author{
David Baker ${ }^{1}$, Charles Roberts ${ }^{1}$, Gareth Pryce ${ }^{1}$, Angray Kang ${ }^{1}$, Monica Marta ${ }^{1}$, Saul \\ Reyes $^{1}$, Klaus Schmierer ${ }^{1}$, Gavin Giovannoni ${ }^{1}$, and Sandra Amor ${ }^{2}$ \\ ${ }^{1}$ Queen Mary University of London \\ ${ }^{2} \mathrm{VU}$ medisch centrum School of Medical Sciences
}

June 23, 2020

\begin{abstract}
Although most autoimmune diseases are considered to be CD4 T-cell or antibody-mediated, many respond to CD20-depleting antibodies that have limited influence on CD4 and plasma cells. This includes rituximab that is used in cancer, rheumatoid arthritis and off-label in a large number of other autoimmunities, notably multiple sclerosis, where ofatumumab is in late stage development and ocrelizumab is approved for use. Recently, the COVID-19 pandemic created concerns about immunosuppression in autoimmunity, leading to cessation or a delay in immunotherapy treatments. However, based on the known and emerging biology of multiple sclerosis and COVID-19, it was hypothesised that whilst B-cell depletion should not necessarily expose people to severe SARS-CoV-2-related issues, it may inhibit protective immunity following infection and vaccination. As such, drug-induced B-cell subset inhibition that controls multiple sclerosis and other autoimmunities, would not influence innate and CD8 T-cell responses, which are central to SARS-CoV-2 elimination, nor the hyper-coagulation and innate inflammation causing severe morbidity. This is supported clinically, as the majority (mortality rate $\mathrm{n}=\sim 5 / 392$ ) of SARS-CoV-2 infected, CD20-depleted people with multiple sclerosis have recovered. However, protective neutralising-antibody and vaccination responses are predicted to be blunted, until naïve B-cells repopulate, based on B-cell repopulation-kinetics and vaccination responses, from published rituximab and unpublished ocrelizumab (NCT00676715, NCT02545868) trial data, shown here. This suggests that it may be possible to undertake dose-interruption to maintain inflammatory disease control in MS and other autoimmune diseases, whilst allowing effective vaccination against SARS-CoV-29, if and when an effective vaccine is available.
\end{abstract}

COVID-19 vaccine-readiness for ocrelizumab and other anti-CD20-depleting therapies in multiple sclerosis and other autoimmune diseases

David Baker ${ }^{1}$, Charles AK Roberts ${ }^{1}$, Gareth Pryce ${ }^{1}$, Angray S Kang ${ }^{1,2}$, Monica Marta ${ }^{1,3}$, Saul Reyes ${ }^{1,3}$, Klaus Schmierer ${ }^{1,3}$, Gavin Giovannoni ${ }^{1,3}$, Sandra Amor ${ }^{1,4}$

1. Blizard Institute, Barts and the London School of Medicine and Dentistry, Queen Mary University of London, London E1 2AT, United Kingdom.

2. Centre for Oral Immunobiology and Regenerative Medicine, Institute of Dentistry, Barts and The London School of Medicine and Dentistry, Queen Mary University of London, United Kingdom

3. Clinical Board: Medicine (Neuroscience), The Royal London Hospital, Barts Health NHS Trust, London, United Kingdom

${ }^{4}$.Pathology Department, Amsterdam UMC, VUmc site, Amsterdam, The Netherlands

Running head: Vaccine readiness of ocrelizumab 
Corresponding author:

Prof. David Baker; BartsMS, Blizard Institute, Barts and the London School of Medicine and Dentistry, Queen Mary University of London, 4 Newark Street, London E1 2AT. Tel: +442078822485; Fax: +442078822180; Email:david.baker@qmul.ac.uk

s.amor@amsterdamumc.nl (S. Amor). Neuropathology, Dept Pathology, Amsterdam UMC Locatie VUmc, ZH 2E 49, De Boelelaan 1117, 1081 HV Amsterdam, The Netherlands

\section{SUMMARY}

Although most autoimmune diseases are considered to be CD4 T-cell or antibody-mediated, many respond to CD20-depleting antibodies that have limited influence on CD4 and plasma cells. This includes rituximab that is used in cancer, rheumatoid arthritis and off-label in a large number of other autoimmunities, notably multiple sclerosis, where ofatumumab is in late stage development and ocrelizumab is approved for use. Recently, the COVID-19 pandemic created concerns about immunosuppression in autoimmunity, leading to cessation or a delay in immunotherapy treatments. However, based on the known and emerging biology of multiple sclerosis and COVID-19, it was hypothesised that whilst B-cell depletion should not necessarily expose people to severe SARS-CoV-2-related issues, it may inhibit protective immunity following infection and vaccination. As such, drug-induced B-cell subset inhibition that controls multiple sclerosis and other autoimmunities, would not influence innate and CD8 T-cell responses, which are central to SARS-CoV-2 elimination, nor the hyper-coagulation and innate inflammation causing severe morbidity. This is supported clinically, as the majority (mortality rate $\mathrm{n}=\sim 5 / 392$ ) of SARS-CoV-2 infected, CD20-depleted people with multiple sclerosis have recovered. However, protective neutralising-antibody and vaccination responses are predicted to be blunted, until naïve B-cells repopulate, based on B-cell repopulation-kinetics and vaccination responses, from published rituximab and unpublished ocrelizumab (NCT00676715, NCT02545868) trial data, shown here. This suggests that it may be possible to undertake dose-interruption to maintain inflammatory disease control in MS and other autoimmune diseases, whilst allowing effective vaccination against SARSCoV-29, if and when an effective vaccine is available.

Keywords : B-cell; CD20; immunotherapy; ocrelizumab; rituximab, rheumatoid arthritis, multiple sclerosis INTRODUCTION

Although many people consider CD4, Th17 cells as central effectors in autoimmunity, response to therapy has indicated that B-cell-depleting drugs exhibit high-efficacy in autoimmune and neuroimmunological diseases [1-3]. As such, not only are CD20-depleting agents approved for B-cell-related cancers, but they are increasingly being used on- and off-label in autoimmune diseases [1,4]. Ocrelizumab has recently been licensed for the treatment of multiple sclerosis (MS) and antibodies including ofatumumab and ublituximab are in development for MS [5-7]. In addition, rituximab, which is approved for rheumatoid arthritis (RA) and pemphigus vulgaris, is frequently used off-label in MS, neuromyelitis optica spectrum disorders (NMOSD), and a variety of other autoimmunities [1, 3, 5, 8]. Such off-label use provides valuable insights into the biology of CD20-depleting therapy [3]. As such, cells within the memory B-cell subsets appear to be important targets for disease control and their depletion and slow-repopulation may, in part, account for the long-term, disease control seen from short-term treatment cycles with alemtuzumab, cladribine, ocrelizumab and rituximab $[2,3,9,10]$. As such, using rituximab to deplete repopulating memory B-cell when they reach pre-defined levels can maintain clinical remission, whilst reducing the frequency of infusions in: RA, NMO, MS and other conditions [3, 11-13]. Translating this knowledge may help improve the benefit: risk balance of ocrelizumab [9]. This is currently, highly relevant as repeated 6-monthly CD20 depletion is associated with $\operatorname{IgM}$ and then IgA and IgG hypogammaglobulinaemia in some individuals and also a small, but increased risk of severe infections [14-16].

Immunological issues of COVID-19. The severe acute respiratory syndrome coronavirus 2 (SARS-CoV2), causing coronavirus disease 2019 (COVID-19) has killed hundreds of thousands of humans in a global pandemic [17]. Severe COVID-19 is often associated with lymphopaenia [18], initially causing great concern 
over the use of immunosuppressive agents. In some cases, this led to the cessation or delay of treatment of autoimmunity 19, 20]. However, it is increasingly evident that lymphopaenia is a consequence rather than a cause of infection [20,21]. Whilst the immune system eliminates SARS-CoV-2 in most individuals (Figure 1), viral escape, immune exhaustion and elevated cytokine release can lead to hyper-activation of the innate immune response, vascular damage and hyper-coagulation (Figure 1), which can lead to significant morbidity, acute respiratory distress, multi-organ failure and, in some cases, death [17,18 22]. Whilst immunotherapy may have some value in treating severe COVID-19 [23], the development of a SARS-CoV-2 vaccine is considered to be important for protecting the uninfected [24]. A vaccination programme should help create herd-immunity against the COVID-19 virus [25]. Therefore, not only is it relevant to determine how disease modifying treatments (DMT) influence susceptibility to infection and length of the carrier state, it is also important to consider how DMT may influence immunity to reinfection and potential vaccine responses [20].

Surprisingly, there is limited, published data concerning the influence of ocrelizumab on immune subsets, vaccine responses, durability of response and the safety of extending infusion intervals. This prompted us to report data available within the public domain that addressed some of these safety concerns [9]. These data indicate that delaying ocrelizumab [9] and rituximab [10, 26] re-infusion should be associated with minor risk of MS reactivation, based on B-cell subset depletion and re-population kinetics [9].

CD20-B-cell depleting agents do not markedly expose people to life-threatening COVID-19. Based on previous understanding of the immune response to SARS-CoV and SARS-CoV-2, animal studies of the elimination of coronaviruses, informative COVID-19 case reports and preliminary reports of COVID-19 pathology [20, 27-29], the biology of MS, MS-treatments, and COVID-19 suggested that halting treatment may cause more harm than good, through ineffective disease control [20, 30]. This suggested that a more pragmatic approach, supported by others in the field of MS and other conditions may be of value [9, 31, 32]. It appears that the innate immune response, and perhaps later anti-viral CD8 T-cell responses, could eliminate the SARS-CoV2, before significant antibody responses had developed [20, 28, 33] (Figure 1). This suggested that most MS treatments that largely exhibit limited persistent effects on the innate immune and CD8 T-cell responses, would have limited influence on COVID-19. As such, SARS-CoV-2 is eliminated by the majority of people with MS and other autoimmunities on immunotherapies, without significant consequences [34-52] (Table 1). Anti-viral antibodies, notably those targeting the receptor binding domain of the viral-spike protein clearly neutralize the virus [53,54] and can contribute to the elimination of the primary SARS-CoV-2 infection in humans [55,56]. However, B-cells do not appear to be an absolute requirement for recovery. This is shown by the recovery of people genetically lacking B-cells, such as with X-linked hypogammaglobulinemia $[57,58]$ and is reinforced by the finding that the vast majority of people treated with CD20 B-cell depleting agents in MS recover from COVID-19 [36-52](Table 1). Furthermore, B-cell depletion is unlikely to influence, or be significantly influenced by, the vascular pathology and hyper-coagulopathy that are major pathological features in COVID-19 that contribute to the acute respiratory distress syndrome, cardiovascular, cerebrovascular and other non-pulmonary morbidities [9, 20, 22, 59, 60] (Figure 1). Importantly, it provides another rationale why immunosuppressive treatments in MS and other autoimmunities [44, 61, 62] have not noticeably influenced COVID-19 susceptibility and prognosis. As such, people with MS appear to respond to SARS-CoV-2 in a similar way to the general population, where severe disease is notably influenced by age and comorbidities, such as diabetes and obesity [18, 43, 44, 62]. Whilst this information is further consolidated by biology and the clinical evidence (Table 1), it may focus attention away from issues of being infected with SARS-CoV-2 [20], to methods of avoiding SARS-CoV-2 infection in uninfected individuals discussed below.

Ocrelizumab is the only DMT that is licenced across the spectrum of primary-progressive and relapsing MS [5]. In comparison to other high efficacy DMT used in MS, it has limited monitoring requirements, fewer restrictions on usage compared to cladribine and alemtuzumab and off-label alternatives are widely used and pharmacovigilance reports have been released [8, 40, 63]. Therefore, it is perhaps not surprising that there is currently more information about the influence of CD20-depletion and COVID-19 disease outcome than for other high-efficacy DMT in MS [49,44] (Table 1). This is consistent with, albeit limited, information in people with rheumatic diseases $[62,64]$ indicating that people generally recover, whilst the few reported 
deaths may be linked to co-morbidities [44]. The suggestion that rituximab treatment may increase risk of infection should be considered in the context of possible sampling biases, though could be supported by data reported in social media from Sweden $[40,52]$ (Table 1). It is evident that both rituximab and ocrelizumab cause IgM hypogammaglobulinaemia in some people within a few treatment cycles and this and IgA and IgG hypogammaglobulinaemia increases with repeated infusions, potentially contributing to infection [9, 14-16]. A delayed IgM response to SARS-CoV-2, which usually appears a few days after symptom onset, may contribute to disease severity $[65,66]$. With time, CD20-depletion is also associated with reduced IgA responses [15] and likewise early IgA responses may also be important for efficient clearance of SARS-CoV-2 $[15,67,68]$. However, as yet there is no compelling evidence that CD20-depletion increases severity of COVID19 compared to the general population [40,41], although in people with genetically dysfunctional B-cells, this has been suggested [58]. In addition, hypogammaglobulinemia may inhibit SARS-CoV-2 cross-reactive, protective-antibodies generated from immunity from previous coronavirus infection, which has been shown at the T and B-cell level [69, 70], and seen previously with SARS and common cold-causing coronaviruses [71]. In contrast, it has been questioned whether benefit may be imparted [37, 43], since B-cell depletion could lead to limited antibody-mediated enhancement of macrophage activity and complement-mediated damage and antibody levels have been associated with severe COVID-19 [67, 72, 73]. Although some people seroconvert and generate an anti-SARS-CoV-2 response, this is expected to be, and sometimes is, blunted or absent due to the inhibition of antibody responses by anti-CD20 B-cell depletion [39, 50]. The antibody titre required for protection against SARS-CoV-2 and the quality and the neutralizing potential of the antibody response after CD20-depletion are currently unknown $[39,50]$. However, even in non-immunosuppressed, notably asymptomatic cases that produce low titre antibody responses, many people do not produce a marked or long-lasting neutralizing antibody response [74-76]. Perhaps, benefit may be achieved by vaccination to boost immunity.

Infection of SARS-CoV-2 infection induces immunity. Although there is much hope for the impact of vaccination on generating immunity to SARS-CoV-2, there is no guarantee of protection or prolongedprotection [24, 76]. Repeated infection is observed with other endemic human coronaviruses that cause common colds suggesting that recurrent reinfections may also occur with SARS-CoV-2 [77]. This strongly supports the contribution of macrophages in viral control and the limited and transient induction of adaptive immunity [77]. Possible re-infection with SARS-Cov-2 has also been suggested by the finding of positive, polymerase chain reaction (PCR) detected SARS-CoV-2 nucleic acid, swabs after a number of negative swabs [78]. However, it is clear that this may be due to non-infective viral particles or artefacts created by sampling location and the testing systems used. As such PCR-positive swabs can be found in faeces long after loss of nasopharyngeal positive PCR findings indicating that the virus may persist for some time and that the PCR test detects fragments of the viral nucleic acid and not necessarily infective virus [79, 80]. Importantly, contact tracing of hundreds of people with positive tests after previous negative tests and hospital discharge, failed to detect any evidence of the production of infective virus and subsequent viral spread to contacts [80]. Importantly, animal model studies show that immunity to SARS-COV-2 develops after primary infection that can rapidly eliminate the virus on re-exposure $(28,29,81]$. This can be stimulated via vaccination in animals and in humans, to generate neutralizing antibodies [82, 83]. In most cases, but not always, neutralizing antibodies persist for a number of months [75,76] and following SARS coronavirus infection, SARS-CoV-specific antibodies were detectable for a year or two before they disappeared [84], probably due to lack of antigenic-stimulation following elimination of the virus. However, as new responses will be generated from CD20+ naïve B-cells, these responses would be anticipated to be blunted by B-cell depleting agents.

CD20 antibodies inhibit vaccine responses. It has been shown that rituximab depletes naïve B-cells in the blood, lymphoid tissue and to some extent the bone marrow and can also disrupt germinal centre formation in secondary lymphoid tissues $(3,85,86]$. Though the influence of ocrelizumab on B-cell subsets and vaccine responses have not been published, trial (NCT02545868) data has been reported in meetings and adopted in the Summary of Product Characteristics produced as part of the regulatory label [63, 87]. Importantly, the data has been deposited on a trial registration site (www.clinicaltrials.gov) allowing data 
extraction, as shown here (Figure 2). It is evident that there is a lower frequency of seroconversion and reduced titre to: 23-valent pneumococcal polysaccharide vaccine (23-PPV) (Figure 2A,B) with or without a booster vaccine (Figure 2C), keyhole limpet haemocyanin (KLH) neoantigen (Figure 2D), tetanus toxoid vaccine (Figure 2E,F) and seasonal influenza vaccines (Figure 2G-I). The percentage of people with MS who gave a positive response (Titre [?] $0.2 \mathrm{IU} / \mathrm{mL}$ or 4 fold increase in titre is baseline levels [?] 0.1IU) to tetanus vaccine 8 weeks after vaccination was $23.9 \%$ in the ocrelizumab group compared to $54.5 \%$ in the control group (no DMT except interferon-beta). The geometric mean anti-tetanus toxoid specific antibody titres at 8 weeks were 3.74 and $9.81 \mathrm{IU} / \mathrm{ml}$, respectively. Although these vaccine booster responses to tetanus toxoid were clearly blunted (Figure $2 \mathrm{C}$ ), the titres were generally above protective levels $(0.16 \mathrm{IU} / \mathrm{mL})$ [88], even at baseline. The percentage of people with MS on ocrelizumab with seroprotective titres against five influenza strains ranged from $20.0-60.0 \%$ and $16.7-43.8 \%$ pre-vaccination and at 4 weeks post-vaccination from 55.6$80.0 \%$ in people treated with ocrelizumab and $75.0-97.0 \%$ in the control group, respectively (Figure 2G). However, haemaggulination inhibition titres were reduced (Figure $2 \mathrm{H}$ ). Likewise, whilst there was a positive response to [?] 5 serotypes in polyvalent pneumococcal vaccine (23-PPV) at 4 weeks after vaccination (71.6\% in the ocrelizumab group and $100 \%$ in the control group), the frequency of seroconversion and antibody titres were however, markedly reduced (Figure 2A). Furthermore, a booster of the 13-PPV vaccine administered 4 weeks later did not markedly enhance the response to 12 serotypes in common with 23-PPV (Figure 2C), further indicating the blunting of the vaccine responses. This was also seen using KLH (Figure 2D). It is likely that this would be reduced further following repeated infusion of ocrelizumab, as hypogammaglobulinaemia, notably of within IgM production develops and increases whilst IgG hypogammaglobulinaemia develops over a longer time frame $(9,15]$.

The relatively poor vaccine response in people treated with ocrelizumab was predictable and consistent with that seen following vaccination in people treated with rituximab, suggesting that this is an issue for all classes of anti-CD20 antibodies used in the treatment of cancer and autoimmune diseases. There was a reduced titre and seroconversion rate (37.5\% vs $75.0 \%$ healthy controls) of people with NMOSD following vaccination against influenza (H1N1) virus 3-5 week after treatment with rituximab [89]. Furthermore, vaccine responses toStreptococcus pneumoniae and influenza were still impaired in people with idiopathic thrombocytopenia and RA six months after treatment [90, 91]. This conclusion was also supported by studies in RA following treatment with rituximab, with a more markedly blunted seroconversion and titre when vaccinated during periods of peripheral B-cell depletion with influenza [92], hepatitis B vaccines [93], PPV-23, KLH [90] and a greater, but still blunted vaccine response 6-10 months after infusion [92]. However, despite a relative lack of memory B-cells, CD19-repopulated individuals could mount a robust recall response, as shown in people with pemphigus vulgaris [94]. This suggests that it is possible to create a time-window to vaccinate an individual due to the differential kinetics of repopulation with pathogenic memory B-cells and naive B-cells that will allow immunity to new infections $[3,95,96]$. In addition, ocrelizumab does not appear to impair pre-existing humoral immunity [97]. This suggests that people with MS who receive the SARS-CoV-2 vaccine if and when it becomes available will be able to start treatment with ocrelizumab without risking vaccine-acquired immunity. However, the effect of ocrelizumab-induced hypogammaglobulinaemia on the levels of protection from prior immunisations is unknown and warrants further investigation.

Repopulation kinetics of ocrelizumab. If COVID-19-related vaccine responses become a key concern among people with MS, or other autoimmune diseases, choosing treatment options, the selection of B-celldepleting agents that allow quick repopulation of B-cells may be relevant for optimum vaccine-readiness. Continuous B-cell depletion with ocrelizumab and rituximab will clearly limit naive B-cell repopulation, however memory B-cell depletion persists for a significant time after depletion with rituximab and alemtuzumab, consistent with the slow-repopulation of this subset [95, 96, 98, 99]. This suggests a possibility for extended interval dosing or dosing interruption to allow immature B-cells to recover to facilitate vaccination, whilst maintaining low levels of pathogenic memory B-cells. Data suggests that this is feasible, at least with rituximab [94]. The timing required for this to occur for ocrelizumab is likely to be substantially longer. Repletion with rituximab occurs within about 6 months of treatment and is completed within 12 months due to repopulation of the immature/mature (naive) B-cell pool [26, 95]. Monthly subcutaneous 
treatment with ofatumumab takes a median of 49 weeks (Range 14-102 weeks) for CD19 B-cell repletion after six $60 \mathrm{mg}$ cycles of treatment and immature (CD19+,CD38+, CD10+) cells repopulate quickly [100]. This may have some merits for ofatumumab if the rapid repopulation of B-cells can be confirmed with more prolonged usage, once ofatumumab is licenced to treat MS. Repopulation of B-cells subsets following ocrelizumab has not been reported previously, but we report here, the influence of ocrelizumab on B-cell subsets from the phase II open label extension study (Figure 3A\&B) [101]. It was found that CD4 and CD8 T-cell numbers were relatively unaffected (Figure 3A\&B), even during active treatment (Figure 3B). CD19 B-cells subsets, including memory (CD19+, CD27+, CD38 $\left.{ }^{\text {low }}\right)$ B-cells are completely depleted during active treatment (Figure 3B). Even following cessation of treatment CD19+ B-cells remain low for 6-12 months after the last infusion (Figure 3A). It is evident, however, that the memory B-cell pool remained depleted for much longer, at least 18 months (Figure 3A \& B) and probably even longer in many individuals [101]. This is consistent with the durability of relapse inhibition and adds further support that cells within this subset are important in MS disease pathogenesis [2,9]. However, there appeared to be some recovery of the naive (CD19+, CD21, IgD+, IgM+) B-cell pool during this time (Figure 3A), suggesting potential to generate new antibody responses, which may be crucial to mount an immune response during infections and vaccinations. As found with rituximab, naive/mature B-cell repopulation will coincide with CD19 repopulation $[26,95]$ and would take a median $62-72$ weeks after three (95\% confidence interval 59.7-73.0 weeks, $\mathrm{n}=51$ ) or four cycles (95\% confidence interval 59.1-85.4. Range 27-175 weeks, $\mathrm{n}=51$ ), respectively [101]. Such levels would require monitoring as there is marked variability in repopulation kinetics between individuals, and is in part a product of the ocrelizumab fixed-dosing schedule, as it is clear that the intensity of B-cell depletion and repopulation speed relates to the body mass index of the individual [102, 103]. This suggests that dose-adjustment for weight may have some benefit, as currently used in the treatment of people with MS with oral cladribine [104]. Cladribine can be considered to be a chemical-CD19 depleting agent that markedly depletes memory B-cells, whilst generally maintaining T-cells within the lower limit of normal. The compound is rapidly eliminated allowing CD19, naive B-cells to recover within a median of 30 weeks after treatment [104-106]. Alemtuzumab is administered at a low dose (36-60mg) per cycle, compared to ocrelizumab (600mg) and rituximab (500-1000mg), and has a relatively short half-life compared to ocrelizumab [107]. Alemtuzumab markedly depletes T-cells and memory B-cells, but naive B-cells rapidly repopulate [96, 99] and vaccine-related antibody responses can be induced within 6 months of infusion [108]. This further supports the concept of a "window for vaccination" for CD20-depleting antibodies.

However, whilst B-cell responses to a variety of different vaccines are clearly inhibited by CD20-depletion, despite some inhibition of CD20 T-cells [95, 109], at least inactivated herpes zoster vaccine can induce T-cells responses [110]. This may be relevant if the CD8 T-cell response is a vital part of the coronavirus specific immunity, as reported for SARS-CoV $[27,111]$. This feature may reduce concern about the limited antibody responses that may be generated following administration of a SARS-CoV-2 vaccine. Although adenoviral vaccines have shown some value in generating neutralizing antibodies and cytopathic T-cells in early human studies [83], live and attenuated viruses are contraindicated in immunosuppressed people [63]. It remains to be seen if SARS-CoV-2 DNA-RNA vaccines [24], will be useful in people taking immunosuppressive agents. However, it is important that people with autoimmunity continue to be offered the benefit that high-efficacy immunotherapy can provide. With time, further knowledge will emerge that may help guide treatment selection within the COVID-19 and post-COVID-19 era.

Funding : This received study received no funding.

Acknowledgements. The authors thank Roche and clinicaltrialsdata.request.com for providing access to the clinical trial data.

Declarations: DB, MM, KS and GG have received compensation for either consultancies and presentations and advisory board activities from Genentech/Roche. However, Roche/Genentech were not involved in the decision to write and submit this manuscript. SA, CAKK, GP, ASK and SR have nothing to disclose. DB has received compensation for activities related to Canbex therapeutics, InMune Biol, Lundbeck, Japan tobacco, Merck, Novartis. MM has received speaking honoraria from Sanofi-Genzyme. KS has received compensation 
for activities related to Biogen, Eisai, Elan, Fiveprime, Lipomed, Merck, Novartis, Sanofi-Genzyme and Teva. GG has received compensation for activities from AbbVie, Actelion, Atara Bio, Bayer-Schering Healthcare, Biogen, Celgene, GW Pharma, GSK, Ironwood, Japanese Tobacco, Merck, Merck-Serono, Mertz, Novartis, Pfizer, Sanofi-Genzyme, Synthon, Takeda, Teva, UCB Pharma and Vertex Pharmaceuticals.

\section{REFERENCES}

1.Du FH, Mills EA, Mao-Draayer Y. Next-generation anti-CD20 monoclonal antibodies in autoimmune disease treatment. Auto Immun Highlights. 2017;8:12

2. Baker D, Marta M, Pryce G, Giovannoni G, Schmierer K. Memory B-cells are major targets for effective immunotherapy in relapsing multiple sclerosis. EBioMedicine. 2017a;16:41-50.

3. Baker D, Pryce G, Amor S, Giovannoni G, Schmierer K. Learning from other autoimmunities to understand targeting of B-cells to control multiple sclerosis. Brain 2018; 141: 2824-2828.

4. Cang S, Mukhi N, Wang K, Liu D. Novel CD20 monoclonal antibodies for lymphoma therapy. J Hematol Oncol. 2012;5:64.

5. Sabatino JJ, Zamvil SS, Hauser SL B-cell therapies in multiple sclerosis. Cold Spring Harb Perspect Med. 2019; 9:a032037

6.Hauser SL, Bar-Or A, Cohen J, Comi G, Correale J, Coyle PK, Cross AH, de seze J et al. 336. Efficacy and safety of ofatumumab versus teriflunomide in relapsing multiple sclerosis: results of the phase 3 ASCLEPIOS I and II trials. Mult scler. 2019; 25 (S2):890-891

7. Fox E, Lovett-Racke AE, Gormley M, et al. A phase 2 multicenter study of ublituximab, a novel glycoengineered anti-CD20 monoclonal antibody, in patients with relapsing forms of multiple sclerosis. Mult Scler. 2020;1352458520918375 [Epub]

8. Ineichen BV, Moridi T, Granberg T, Piehl F. Rituximab treatment for multiple sclerosis. Mult Scler. 2020;26(2):137-152.

9. Baker D, Pryce G, James LK, Marta M, Schmierer K. The ocrelizumab phase II extension trial suggests the potential to improve the risk:benefit balance in multiple sclerosis. Mult Scler Relat Disord. 2020a. in press.

10. Juto A, Fink K, Nimer F, Piehl F. Interrupting rituximab treatment in relapsing-remitting multiple sclerosis; no evidence of rebound disease activity. Mult Scler Relat Disord. 2020, 37:101468. [Epub]

11. Trouvin AP, Jacquot S, Grigioni S, Curis E, Dedreux I, Roucheux A, Boulard H, Vittecoq O, et al. Usefulness of monitoring of B-cell depletion in rituximab-treated rheumatoid arthritis patients in order to predict clinical relapse: a prospective observational study. Clin Exp Immunol; 180:11-8.

12. Kim SH, Kim W, Li XF, Jung IJ, Kim HJ. Repeated treatment with rituximab based on the assessment of peripheral circulating memory B-cells in patients with relapsing neuromyelitis optica over 2 years. Arch Neurol. 2011;68(11):1412-1420

13. Novi G, Fabbri S, Bovis F, et al. Tailoring B-cells depleting therapy in MS according to memory B-cells monitoring: a pilot study. P971. Mult Scler. 2019; 25: (S2) 509-510.

14.Marcinno A, Marnetto F, Valentino P, et al. Rituximab-induced hypogammaglobulinemia in patients with neuromyelitis optica spectrum disorders. Neurol Neuroimmunol Neuroinflamm. 2018;5(6):e498. Published 2018 Sep 13. doi:10.1212/NXI.0000000000000498

15. Derfuss T, Weber MS, Hughes R, Wang Q, Sauter A, Koendgen H, Hauser SL, Bar-Or A, et al. Serum immunoglobulin levels and risk of serious infections in the pivotal Phase III trials of ocrelizumab in multiple sclerosis and their open-label extensions. 65. Mult scler 2019; 25 (S2) 20-21 
16. Luna G, Alping P, Burman J, Fink K, Fogdell-Hahn A, Gunnarsson M, Hillert J, Langer-Gould A, et al. Infection risks among patients with multiple sclerosis treated with fingolimod, natalizumab, rituximab, and injectable therapies JAMA Neurol. 2019; 77: doi:10.1001/jamaneurol.2019.3365 [Epub]

17. Baloch S, Baloch MA, Zheng T, Pei X. The Coronavirus Disease 2019 (COVID-19) Pandemic. Tohoku J Exp Med. 2020;250(4):271-278. doi:10.1620/tjem.250.271

18.Huang C, Wang Y, Li X, et al. Clinical features of patients infected with 2019 novel coronavirus in Wuhan, China [published correction appears in Lancet. 2020 Jan 30;:]. Lancet. 2020;395(10223):497-506.

19. Brownlee W, Bourdette D, Broadley S, Killestein J, Ciccarelli O. Treating multiple sclerosis and neuromyelitis optica spectrum disorder during the COVID-19 pandemic. Neurology. 2020; 94:949-952.

20. Baker D, Amor S, Kang AS, Schmierer K, Giovannoni G. The underpinning biology relating to multiple sclerosis disease modifying treatments during the COVID-19 pandemic Mult Scler Relat Disord. 2020b; 43:102174. doi: 10.1016/j.msard.2020.102174.

21. Xu X, Chang XN, Pan HX, Su H, Huang B, Yang M, Luo DJ, Weng MX, et al. Pathological changes of the spleen in ten patients with coronavirus disease 2019(COVID-19) by postmortem needle autopsy]. Zhonghua Bing Li Xue Za Zhi. 2020 Jun 8;49(6):576-582.

22. Henry BM, Vikse J, Benoit S, Favaloro EJ, Lippi G. Hyperinflammation and derangement of reninangiotensin-aldosterone system in COVID-19: A novel hypothesis for clinically suspected hypercoagulopathy and microvascular immunothrombosis. Clin Chim Acta. 2020;507:167-173.

23. AminJafari A, Ghasemi S. The possible of immunotherapy for COVID-19: A systematic review. Int Immunopharmacol. 2020;83:106455. doi:10.1016/j.intimp.2020.106455

24. Thanh Le T, Andreadakis Z, Kumar A, Roman RG, Tollefsen S, Saville M, Mayhew S. The COVID-19 vaccine development landscape. Nat Rev Drug Discov. 2020;19:305-306.

of print.

25.Randolph HE, Barreiro LB. Herd Immunity: Understanding COVID-19.Immunity. 2020 May 19;52:737741.

26. Bar-Or A, Calabresi PA, Arnold D, Markowitz C, Shafer S, Kasper LH, Waubant E, Gazda S, et al. Rituximab in relapsing-remitting multiple sclerosis: a 72-week, open-label, phase I trial. Ann Neurol. 2008 Mar;63(3):395-400. doi: 10.1002/ana.21363.

27. Channappanavar R, Fett C, Zhao J, Meyerholz DK, Perlman S. Virus-specific memory CD8 T-cells provide substantial protection from lethal severe acute respiratory syndrome coronavirus infection. J Virol. 2014;88(19):11034-11044.

28. Bao L, Deng W, Gao H, Xiao C, Liu J, Xue J, Lv Q Liu J, et al. Reinfection could not occur in SARS-CoV-2 infected rhesus macaques. BioR Xiv 2020.03.13.990226; doi: https://doi.org/10.1101/2020.03.13.990226

29. Bao L, Deng W, Huang B, Gao H, Liu J, Ren L, Wei Q, Yu P, et al. The pathogenicity of SARS-CoV-2 in hACE2 transgenic mice. Nature. 2020;10.1038/s41586-020-2312-y.

30. Giovannoni G, Hawkes C, Lechner-Scott J, Levy M, Waubant E, Gold J. The COVID-19 pandemic and the use of MS disease-modifying therapies. Mult Scler Relat Disord. 2020;39:102073. doi:10.1016/j.msard.2020.102073

31.Berger JR, Brandstadter R, Bar-Or A. COVID-19 and MS disease-modifying therapies. Neurol Neuroimmunol Neuroinflamm. 2020;7(4):e761.

32. Favalli EG, Ingegnoli F, De Lucia O, Cincinelli G, Cimaz R, Caporali R. COVID-19 infection and rheumatoid arthritis: Faraway, so close! Autoimmun Rev. 2020;19:102523 
33. Wang B, Wang L. Kong X, Geng J, Xiao D, Ma C, Jiang XM, Wang PH. Long term coexistence of SARS-CoV-2 with antibody response in COVID-19 patients. J Med Virol 2020a Doi:10.1002/jmv.25946

34. Anand P, Slama MCC, Kaku M, Ong C, Cervantes-Arslanian AM, Zhou L, David WS, Guidon AC. COVID-19 in patients with myasthenia gravis. Muscle Nerve. 2020 May 11:10.1002/mus.26918. doi: 10.1002/mus.26918.

35.Dworakowska D, Grossman AB. Thyroid disease in the time of COVID-19. Endocrine. 2020 Jun 7. doi: 10.1007/s12020-020-02364-8.

36. Salvarani C, Bajocchi G, Mancuso P, Galli E, Muratore F, Boiardi L, Catanoso M, Pipitone N et al. Susceptibility and severity of COVID-19 in patients treated with bDMARDS and tsDMARDs: a populationbased study. Ann Rheum Dis. 2020 May 28:annrheumdis-2020-217903. doi: 10.1136/annrheumdis-2020217903

37. Novi G, Mikulska M, Briano F, Toscanini F, Tazza F, Uccelli A, Inglese M. COVID-19 in a MS patient treated with ocrelizumab: does immunosuppression have a protective role? Mult Scler Relat Disord. 2020 Apr 15;42:102120. doi: 10.1016/j.msard.2020.102120

38. Louapre C, Maillart E, Roux T, et al. Patients with MS treated with immunosuppressive agents: Across the COVID-19 spectrum. Rev Neurol . 2020;176(6):523-525.

39. Montero-Escribano P, Matías-Guiu J, Gómez-Iglesias P, Porta-Etessam J, Pytel V, Matias-Guiu JA. Anti-CD20 and COVID-19 in multiple sclerosis and related disorders: A case series of 60 patients from Madrid, Spain. Mult Scler Relat Disord. 2020 May 7;42:102185. doi: 10.1016/j.msard.2020.102185

40. Safavi F, Nourbakhsh B, Azimi AR. B-cell depleting therapies may affect susceptibility to acute respiratory illness among patients with multiple sclerosis during the early COVID-19 epidemic in Iran. Mult Scler Relat Disord. 2020 May 13;43:102195.

41. Hughes R, Pedotti R, Koendgen H. COVID-19 in persons with multiple sclerosis treated with ocrelizumab - A pharmacovigilance case series. Mult Scler Relat Disord. 2020 May 16;42:102192. doi: 10.1016/j.msard.2020.102192.

42. Suwanwongse K, Shabarek N. Benign course of COVID-19 in a multiple sclerosis patient treated with Ocrelizumab. Mult Scler Relat Disord. 2020 May 15:102201. doi: 10.1016/j.msard.2020.102201

43. Ghajarzadeh M, Mirmosayyeb O, Barzegar M, Nehzat N, Vaheb S, Shaygannejad V, Maghzi AH. Favorable outcome after COVID-19 infection in a multiple sclerosis patient initiated on ocrelizumab during the pandemic. Mult Scler Relat Disord. 2020; 43:102222. doi: 10.1016/j.msard.2020.102222. [Epub]

44. Chaudhry F, Bulka H, Rathnam AS, Said OM, Lin J, Lorigan H, Bernitsas E, Rube J, et al. COVID-19 in multiple sclerosis patients and risk factors for severe infection. doi: https://doi.org/10.1101/2020.05.27.20114827

45.Sormani MP; Italian Study Group on COVID-19 infection in multiple sclerosis. An Italian programme for COVID-19 infection in multiple sclerosis. Lancet Neurol. 2020 Jun;19(6):481-482.

46. Salter A. iWiMS MS Covid-19. 13 May 2020 (https://youtu.be/XAiBJ2sphkU);

47. Assmuth Oreja CS. iWiMS MS Covid-19. 6 May 2020 (https://youtu.be/cp0rtxq_k2Y)

48. van der Welt A, Health A. iWiMS MS Covid-19. 6 May 2020 (https://youtu.be/cp0rtxq_k2Y)

49. Louapre C, Collongues N, de Seze J, iWiMS MS Covid-19. 13 May 2020b (https://youtu.be/cp0rtxq_k2Y)

50.Meca-Lallana V, Aguirre C, del Río B, Cardeñoso L, Alarcon T, Vivancos J. COVID-19 in 7 multiple sclerosis patients in treatment with anti CD20 therapies. Mult scler Rel Disord. 2020 Doi https://doi.org/10.1016/j.msard.2020.102306 
51. BarzegarM, Mirmosayyeb O, Ghajarzade M, vaheb S, Shaygannejad V, Vosoughi R. Characteristics of COVID-19 disease in multiple sclerosis patients. Mult Scler Rel Disord. Doi/https://doi.org/10.1016/j.msard.2020.102276

52. Hillert J. iWiMS MS Covid-19. 20 May 2020 (https://youtu.be/z4sRBQEv0yE);

53. Suthar MS, Zimmerman M, Kauffman R, Mantus G, Linderman S, Vanderheiden A, Nyhoff L, Davis $\mathrm{C}$, et al. Rapid generation of neutralizing antibody responses in COVID-19 patients. Medrxiv doi: https://doi.org/10.1101/2020.05.03.20084442.

54. Bertoglio, F, Meier, D, Langreder, N, Steinke S, Rand U, Simonelli L, Heine PA, Ballmann R, et al. SARSCoV-2 neutralizing human recombinant antibodies selected from pre-pandemic healthy donors binding at RBD-ACE2 interface. BioRXiv doi: https://doi.org/10.1101/2020.06.05.135921.

55. Zeng QL, Yu ZJ, Gou JJ, et al. Effect of convalescent plasma therapy on viral shedding and survival in COVID-19 patients. J Infect Dis. 2020;jiaa228. doi:10.1093/infdis/jiaa228 [Epub]

56. Ye M, Fu D, Ren Y, et al. Treatment with convalescent plasma for COVID-19 patients in Wuhan, China. J Med Virol. 2020;10.1002/jmv.25882. doi:10.1002/jmv.25882

57. Soresina A, Moratto D, Chiarini M, Paolillo C, Baresi G, Focà E, Bezzi M, Baronio B, et al.Two X-linked agammaglobulinemia patients develop pneumonia as COVID-19 manifestation but recover. Pediatr Allergy Immunol. 2020 Apr 22:10.1111/pai.13263. doi: 10.1111/pai.13263

58. Quinti I, Lougaris V, Milito C, Cinetto F, Pecoraro A, Mezzaroma I, Mastroianni CM, Turriziani O, et al. A possible role for B-cells in COVID-19? Lesson from patients with agammaglobulinemia. J Allergy Clin Immunol. 2020 Apr 22:S0091-6749(20)30557-1. doi: 10.1016/j.jaci.2020.04.013.

59. Ackermann M, Verleden SE, Kuehnel M, Haverich A, Welte T, Laenger F, Vanstapel A, Werlein C et al. Pulmonary Vascular Endothelialitis, Thrombosis, and Angiogenesis in Covid-19. N Engl J Med. 2020 May 21. doi: 10.1056/NEJMoa2015432

60.Tseng YH, Yang RC, Lu TS. Two hits to the renin-angiotensin system may play a key role in severe COVID-19 [published online ahead of print, 2020 Jun 3]. Kaohsiung J Med Sci. 2020;10.1002/kjm2.12237. doi:10.1002/kjm2.12237

61. Monti S, Balduzzi S, Delvino P, Bellis E, Quadrelli VS, Montecucco C. Clinical course of COVID-19 in a series of patients with chronic arthritis treated with immunosuppressive targeted therapies. Ann Rheum Dis. 2020;79:667-668

62. Gianfrancesco M, Hyrich KL, Al-Adely S, et al. Characteristics associated with hospitalisation for COVID-19 in people with rheumatic disease: data from the COVID-19 Global Rheumatology Alliance physician-reported registry. Ann Rheum Dis. 2020;annrheumdis-2020-217871. doi:10.1136/annrheumdis2020-217871

63. Ocrevus(r) European public assessment report. 7/01/2019 update. Summary of product characteristics. https://www.ema.europa.eu/en/documents/product-information/ocrevus-epar-product-information_en.pdf. Accessed 5 January 2020.

64. Fallet B, Kyburz D, Walker UA. Mild course of Coronavirus disease 2019 and spontaneous severe acute respiratory syndrome coronavirus 2 clearance in a patient with depleted peripheral blood B-cells due to treatment with rituximab. Arthritis Rheumatol. 2020;10.1002/art.41380.

65.Xiang F, Wang X, He X, Peng Z, Yang B, Zhang J, Zhou Q, Ye H, et al. Antibody detection and dynamic characteristics in patients with COVID-19.Clin Infect Dis. 2020 Apr 19:ciaa461. doi: 10.1093/cid/ciaa461. 
66. Shen L, Wang C, Zhao J, Tang X, Shen Y, Lu M, Ding Z, Huang C, et al. Delayed specific IgM antibody responses observed among COVID-19 patients with severe progression. Emerg Microbes Infect. 2020 Dec;9(1):1096-1101.

67. Yu HQ, Sun BQ, Fang ZF, Zhao JC, Liu XY, Li YM, Sun XZ, Liang HF, et al. Distinct features of SARS-CoV-2-specific IgA response in COVID-19 patients. Eur Respir J. 2020a Jun 8:2001526. doi: $10.1183 / 13993003.01526-2020$

68. Dahlke C, Heidepriem J, Kobbe R, Santer R, Koch T, Fathi A, Ly ML, Schmiedel S, et al. Distinct early IgA profile may determine severity of COVID-19 symptoms: an immunological case series. MedRXiv doi: https://doi.org/10.1101/2020.04.14.20059733

69. Grifoni A, Weiskopf D, Ramirez SI, Mateus J, Dan JM, Moderbacher CR, Rawlings SA, Sutherland A, et al. Targets of T Cell Responses to SARS-CoV-2 Coronavirus in Humans with COVID-19 Disease and Unexposed Individuals Cell. 2020:S0092-8674(20)30610-3

70. Ng K, Faulkner N, Cornish G, Rosa A, Earl C, Wrobel A, Benton D, Roustan C, et al. Pre-existing and de novo humoral immunity to SARS-CoV-2 in humans. BioRxiv 2020. doi: https://doi.org/10.1101/2020.05.14.095414.

71. Che XY, Qiu LW, Liao ZY, Wang, Wen K, Pan YX, Hao W, Mei YB, et al. Antigenic Cross-Reactivity between Severe Acute Respiratory Syndrome-Associated Coronavirus and Human Coronaviruses 229E and OC43, The Journal of Infectious Diseases 2005; 191: 2033-2037.

72. Negro F. Is antibody-dependent enhancement playing a role in COVID-19 pathogenesis? Swiss Med Wkly. 2020;150:w20249.

73.Magro C, Mulvey JJ, Berlin D, Nuovo G, Salvatore S, Harp J, Baxter-Stoltzfus A, Laurence J. Complement associated microvascular injury and thrombosis in the pathogenesis of severe COVID-19 infection: a report of five cases. Transl Res. 2020 Apr 15:S1931-5244(20)30070-0. doi: 10.1016/j.trsl.2020.04.007. Online ahead

74. Xiao T, Wang Y, Yuan J, Ye H, Wei L, Liao X, Wang, H, Qian S, et al. Early viral clearance and antibody kinetics of COVID-19 among asymptomatic carriers. medRxiv 2020.04.28.20083139; doi: https://doi.org/10.1101/2020.04.28.20083139

75. Brochot E, Demey B, Touze A, Belouzard Sm Dubuisson J, Schmit JL, Duverlie G, Francois C, et al. Anti-Spike, anti-nucleocapsid and neutralizing antibodies in SARS-CoV-2 inpatinets and asymptomatic carriers. MedRXiv.2020. https://doi.org/10.1101/2020.05.12.20098236.

76. Liu T, Wu S, Tao H, Zeng G, Zhou F, Guo, F, Wang X Prevalence of IgG antibodies to SARS-CoV-2 in Wuhan -implications for the ability to produce long-lasting protective antibodies against SARS-CoV-2. MedRXiv. https://doi.prg//10.1101/2020.06.13.20130252.

77. Galanti M, Shaman J. Seasonal cold-inducing coronavirus can be repeatedly detected in some individuals medRxiv doi:https://doi.org/10.1101/2020.04.27.20082032

78. Ravioli S, Ochsner H, Lindner G. Reactivation of COVID-19 pneumonia: a report of two cases

J Infect. 2020: S0163-4453(20)30279-6.

79. Wang QX, Huang KC, Qi L, Zeng XH, Zheng SL. No infectious risk of COVID-19 patients with long-term fecal 2019-nCoV nucleic acid positive. Eur Rev Med Pharmacol Sci. 2020b;24(10):5772-5777.

80. Korean Centre for Disease Control and Prevention. Findings from investigation and analysis of re-positive cases. Notice 2020-05-19 2020-12-31. https/is.cdc.gov.kr/upload_comm/syview/doc.html?fn=159118745823700.pdf\&rs=/upload_comm/docu/0030. 
81.Chandrashekar A, Liu J, Martinot AJ, McMahan K, Mercado NB, Peter L, Tostanoski LH, Yu J, et al. SARS-CoV-2 infection protects against rechallenge in rhesus macaques. Science. 2020 May 20:eabc4776. doi: $10.1126 /$ science.abc4776.

82. Yu J, Tostanoski LH, Peter L, Mercado NB, McMahan K, Mahrokhian SH, Nkolola JP, Liu J, et al. DNA vaccine protection against SARS-CoV-2 in rhesus macaques. Science. 2020b May 20:eabc6284. doi: $10.1126 /$ science.abc6284.

83. Zhu FC, Li YH, Guan XH, Hou LH, Wang WJ, Li JX, Wu SP, Wang BS et al. Safety, tolerability, and immunogenicity of a recombinant adenovirus type- 5 vectored COVID-19 vaccine: a dose-escalation, open-label, non-randomised, first-in-human trial. Lancet. 2020; S0140-6736(20)31208-3.

84.Wu LP, Wang NC, Chang YH, Tian ZY, Na DY, Zhang LY, Zheng L, Lan T, et al. Duration of antibody responses after severe acute respiratory syndrome. Emerg Infect Dis. 2007;13:1562-1564.

85.Cioc AM, Vanderwerf SM, Peterson BA, Robu VG, Forster CL, Pambuccian SE. Rituximab-induced changes in hematolymphoid tissues found at autopsy. Am J Clin Pathol. 2008;130(4):604-612.

86 Ramwadhdoebe TH, van Baarsen LGM, Boumans MJH, Bruijnen STG, Safy M, Berger FH, Semmelink JF, van der Laken CJ et al. Effect of rituximab treatment on T and B-cell subsets in lymph node biopsies of patients with rheumatoid arthritis. Rheumatology (Oxford). 2019;58(6):1075-1085.

87. Stokmaier D, Winthrop K, Chognot C, Evershed J, Manfrini M, McNamara J, Bar-Or A. Effect of ocrelizumab on vaccine responses in patients with multiple sclerosis (S36.002). Neurology; 2018; 90 (15 Suppl): S36.002

88. Simonsen, O, Bentzon MW, Heron I. ELISA for the routine determination of antitoxic immunity to tetanus. J. Biol. Stand. 1986; 14:231-239.

89. Kim W, Kim SH,Huh SY, Kong SY, Choi YJ, Cheong HJ Kim HJ, Reduced antibody formation after influenza vaccination in patients with neuromyelitis optica spectrum disorder treated with rituximab. Eur J Neurol 2013; 20: 975-980.

90.Bingham CO, Looney RJ, Deodhar A, Halsey N, Greenwald M, Codding C, Trzaskoma B, Martin F, et al. Immunization responses in rheumatoid arthritis patients treated with rituximab:results from a controlled clinical trial. Arthritis Rheum. 2010; 62:64-74.

91.Nazi I, Kelton JG, Larche M, Snider DP, Heddle NM, Corowther MA, Cook RJ, Tinmouth AT et al. The effect of rituximab on vaccine responses in patients with immune thrombocytopenia. Blood. 2013;122:19461953.

92. van Assen S, Holvast A, Telgt DS, et al. Patients with humoral primary immunodeficiency do not develop protective anti-influenza antibody titers after vaccination with trivalent subunit influenza vaccine. Clin Immunol. 2010;136(2):228-235. doi:10.1016/j.clim.2010.03.430.

93. Richi P, Alonso O, Martin MD, Gonzalez-Hombrado L, Navio T, Salido M, Llorente J, Andreu-Vazquez $\mathrm{C}$, et al. Evaluation of the immune response to hepatitis B vaccine in patients on biological therapy: results of the RIER cohort study. Clin Rheumatol. 2020; 10.1007/s10067-020-05042-2 [Epub].

94. Cho A, Bradley B, Kauffman R, Priyamvada L, Kovalenkov Y, Feldman R, Wrammert J. Robust memory responses against influenza vaccination in pemphigus patients previously treated with rituximab. JCI Insight. 2017;2(12):e93222.

95. Palanichamy A, Jahn S, Nickles D, Derstine M, Abounasr A, Hauser SL, Baranzini SE, Leppert D, et al. Rituximab efficiently depletes increased CD20-expressing T-cells in multiple sclerosis patients. J Immunol. 2014 193(2):580-586

96. Baker D, Herrod SS, Alvarez-Gonzalez C, Giovannoni G, Schmierer K. Interpreting lymphocyte reconstitution data from the pivotal phase 3 trials of alemtuzumab. JAMA Neurol. 2017b;74(8):961-969. 
97. Ziemssen T, Bar-Or A, Arnold DL, Comi G, Hartung HP, Hauser SL, Lublin K, Slemaj K et al. P 2 Effect of ocrelizumab on humoral immunity markers in the phase iii, double-blind, double-dummy, IFN $\beta$ -1a-controlled OPERA I and OPERA II studies . Clin Neurophysiol2017;128:e326-7.

98. Roll P, Palanichamy A, Kneitz C, Dorner T, Tony HP. Regeneration of B-cell subsets after transient B-cell depletion using anti-CD20 antibodies in rheumatoid arthritis. Arthritis Rheum. 2006;54(8):2377-2386.

Sabatino JJ, Zamvil SS, Hauser SL. B-Cell Therapies in Multiple Sclerosis. Cold Spring Harb Perspect Med. 2019; 9(2):a032037.

99. Akgün K, Blankenburg J, Marggraf M, Haase R, Ziemssen T. Event-Driven Immunoprofiling predicts return of disease activity in alemtuzumab-treated multiple sclerosis. Front Immunol. 2020 Jan 31;11:56. doi: 10.3389/fimmu.2020.00056

100. Bar-Or A, Grove RA, Austin DJ, Tolson JM, VanMeter SA, Lewis EW, Derosier FJ, Lopez MC, et al. Subcutaneous ofatumumab in patients with relapsing-remitting multiple sclerosis: The MIRROR study.Neurology. 2018 May 15;90(20):e1805-e1814.

101. WA21493 Clinical study report 2016. WA21493-Phase II, multicenter, randomized parallel-group, partially blinded, placebo, Avonex (R controlled dose finding study to evaluate the efficacy as measured by brain MRI lesions and safety of 2 dose regimens of ocrelizumab in patients with RRMS. Report No. 1062910. March 2016.

102. Signoriello E, Bonavita S, Di Pietro A, et al. BMI influences CD20 kinetics in multiple sclerosis patients treated with ocrelizumab [published online ahead of print, 2020 May 17]. Mult Scler Relat Disord. 2020;43:102186.

103. Kletzl H, Gibiansky E, Petry C, Francois Mercier F, Guenther A, Wang Q, Model F, Kappos L, et al. Pharmacokinetics, pharmacodynamics and exposure-response analyses of ocrelizumab in patients with multiple sclerosis. Neurol, 2019; 92 (15 Supplement) N4.001.

104. Comi G, Cook S, Giovannoni G, Rieckmann P, Sørensen PS, Vermersch P, Galazka A, Nolting A et al. Effect of cladribine tablets on lymphocyte reduction and repopulation dynamics in patients with relapsing multiple sclerosis. Mult Scler Relat Disord. 2019;29:168-174.

105. Hermann R, Karlsson MO, Novakovic AM, Terranova N, Fluck M, Munafo A. The clinical pharmacology of cladribine tablets for the treatment of relapsing multiple sclerosis. Clin Pharmokinet. 2019; 58:283-297.

106. Baker D, Pryce G, Herrod SS, Schmierer K. Potential mechanisms of action related to the efficacy and safety of cladribine. Mult Scler Relat Disord. 2019 30:176-186.

107. Li Z, Richards S, Surks HK, Jacobs A, Panzara MA. Clinical pharmacology of alemtuzumab, an anti-CD52 immunomodulator, in multiple sclerosis. Clin Exp Immunol. 2018;194(3):295-314.

108. McCarthy CL, Tuohy O, Compston DA, Kumararatne DS, Coles AJ, Jones JL. Immune competence after alemtuzumab treatment of multiple sclerosis. Neurology. 2013;81(10):872-876.

109. Gingele S, Jacobus TL, Konen FF, Hummert MW, Suhs KW, Schwenkenbecher P, Ahlbrecht J, Mohn N, et al.. Ocrelizumab depletes CD20+ T Cells in multiple sclerosis patients. Cells. 2018; 8:12.

110. Parrino J, McNeil SA, Lawrence SJ, et al. Safety and immunogenicity of inactivated varicella-zoster virus vaccine in adults with hematologic malignancies receiving treatment with anti-CD20 monoclonal antibodies. Vaccine. 2017;35(14):1764-1769.

111.Ng OW, Chia A, Tan AT, et al. Memory T-cell responses targeting the SARS coronavirus persist up to 11 years post-infection. Vaccine. 2016;34:2008-2014

Table 1 . Infection with SARS-CoV2 in people treated with CD20-depleting antibodies in MS 


\begin{tabular}{llllll} 
CD20 & Total No. & No. & No. Intensive & No. Deaths & Reference \\
Antibody & infected & Hospitalised & Care & & 36 \\
Ocrelizumab & 1 & 1 & 0 & 0 & 0 \\
Ocrelizumab & 1 & 1 & 0 & 0 & 37 \\
Ocrelizumab & 2 & 0 & 0 & 0 & 38 \\
Ocrelizumab & 34 & 2 & 0 & N.R. & 40 \\
Ocrelizumab & 100 & 26 & 5 & 0 & 41 \\
Ocrelizumab & 1 & 1 & 0 & 0 & 42 \\
Ocrelizumab & 1 & 0 & 0 & N.R. & 43 \\
Ocrelizumab & 11 & 5 & 2 & 0 & 44 \\
Ocrelizumab & 26 & N.R. & 2 & 2 & 45 \\
Ocrelizumab & 59 & N.R. & N.R. & N.R. & 46 \\
Ocrelizumab & 10 & N.R. & N.R. & 0 & 47 \\
Ocrelizumab & 2 & 0 & 0 & 0 & 48 \\
Ocrelizumab & 25 & 7 & 2 & 0 & 49 \\
Ocrelizumab & 7 & 3 & 0 & $\mathbf{2}$ & 44 \\
Subtotal & $\mathbf{2 8 0}$ & $\mathbf{4 5}$ & $\mathbf{1 1}$ & 1 & 38 \\
Rituximab & 2 & N.R. & 1 & 0 & 39 \\
Rituximab & 7 & 1 & 0 & 0 & 50 \\
Rituximab & 21 & {$[?] 2$} & 0 & 1 & 51 \\
Rituximab & 1 & 1 & 1 & N.R. \\
Rituximab & 41 & 9 & 6 & N.R. \\
Rituximab & 6 & N.R. & N.R. & 0 & 46 \\
Rituximab & 9 & N.R. & N.R. & 1 & 45 \\
Rituximab & 24 & $\mathbf{2 1}$ & 5 & $\mathbf{3}$ & 48 \\
Subtotal & $\mathbf{1 1 1}$ & 0 & $\mathbf{1 3}$ & 0 & 48 \\
Ofatumumab & 1 & $\mathbf{6 4}$ & $\mathbf{2 4}$ & $\mathbf{5}$ & \\
Total & $\mathbf{3 9 2}$ & & & & \\
\hline & & & 0 & & \\
\hline
\end{tabular}

Number of people that have been infected with the COVID-19 virus that have been documented in case reports and registries from published and social media reports. It is not possible to exclude that people reported in case reports, registries and pharmacovigilance studies are repeat reporting. In addition, infection was defined by symptoms and was not always confirmed via viral nucleic acid testing or serology. N.R. Not reported

\section{FIGURE LEGENDS}

Figure 1. Pathobiology of COVID-19. SARS-CoV-2 infects cells in the lung and the gut via the angiotensin converting enzyme two (ACE2). This blocks ACE2-induced formation of anti-oxidant angiotensin, facilitating oxygen free-radical formation and vascular damage. The innate immune response provides the initial line of defence against the virus, while a CD8 anti-viral T-cell response and neutralizing and complement-fixing antibody response serve to remove the virus in the majority of people. However, the virus triggers suppression of interferon responses and other viral escape mechanisms that in a minority of people stimulate the innate immune response leading to lymphocyte apoptosis that blocks their regulatory signals and in some cases releases a cytokine storm that drives hyper-innate-inflammation. This in part causes acute respiratory distress. Importantly, this augments vascular damage that accentuates the respiratory distress and leads to von Willebrand factor release into the blood. This contributes to the formation of microthrombi, contributing to respiratory distress and vascular embolism that may be fatal. Adapted from Henry et al. 2020 [22].

Figure 2 . Ocrelizumab inhibits vaccination responses.People with multiple sclerosis did not received ocrelizumab (control) or were infused with $300 \mathrm{mg}$ ocrelizumab on day 0 and 15 and were vaccinated from week 12-24 after ocrelizumab. The experimental details and results were from www.clinicaltrials.gov NCT02545868 
[87]. The results show: (A) The frequency of seroconversion in people treated with ocrelizumab following injection pneumococcal 23-PPV vaccine, 4 weeks after vaccination $(\mathrm{n}=66-68)$. A 23-PPV vaccine response against a serotype was defined by a 2 -fold increase in anti-pneumococcal antibody or $>1 \mu \mathrm{g} / \mathrm{ml}$ compared with pre-vaccination levels, following Food and Drug Administration guidance. (B) The titre of response to the initial challenge with 23-PPV 4 weeks after vaccination. (C) The frequency of seroconversion in people treated with ocrelizumab following injection of a booster pneumococcal 13-PPV vaccine 4 weeks after 23-PPV. ( $\mathrm{n}=33-34)$. The frequency of responders is shown 8 weeks after $23-\mathrm{PPV}$ vaccination. (D) The geometric mean and 95\% confidence interval (CI) anti-tetanus toxoid antibody levels measured by ELISA before and following vaccination $(\mathrm{n}=34-68)$. (E,F) The geometric mean and 95\% CI titre of (E) IgM or (F) IgG KLH specific antibody after vaccination with keyhole limpet haemocyanin at baseline, week 4 and week 8 started 12 weeks after ocrelizumab infusion $(\mathrm{n}=34-68)$. (G-I). The response to: A/California/7/2009 (H1N1. n=33-35); B/Phuket/3073/2013 (BPH. n=31-33), A/Switzerland/ 9715293/2013 (H3N2. n=27-30), B/Brisbane/60/2008 (BBR. $\mathrm{n}=16-18$ ), A/Hong Kong/4801/2014 (AHK. $\mathrm{n}=5-6$ ) influenza strain vaccination 12 weeks after ocrelizumab infusion was assessed. The results represent $(\mathrm{G})$ the percentage of people with seroconversion, defined either a pre-vaccination haemagglutination inhibition (HI) titre $<10$ and [?]40 at 4 weeks or a pre-vaccination [?]10 and at least a 4 fold increase in HI titre, and seroprotection defined by titres $>40$ at 4 weeks after vaccination. $(\mathrm{H})$ The change in the geometric mean HI titres before and after vaccination (I) The percentage of people with a 4 -fold increase in strain-specific $>40$ ) at 4 weeks after vaccination.

Figure 3. Long-term depletion of memory B-cells induced by ocrelizumab. These data were extracted from the ocrelizumab phase II clinical study report [101], supplied by the trial sponsor via the www.clinicaltrialdatarequest.com portal. (A) The data represents the mean percentage change from baseline, defined as the last observation up to first day of ocrelizumab treatment. The subjects received placebo and three cycles of $600 \mathrm{mg}$ ocrelizumab every 24 weeks. This was followed by a treatment-free period to monitor B-cell repletion in the phase II extension study. The time represents the period from the last ocrelizumab infusion $(\mathrm{n}=22-43)$. Naive $(\mathrm{CD} 19+, \mathrm{CD} 21+, \mathrm{IgD}+, \mathrm{IgM}+)$ and memory B-cell (CD19+, CD27+, CD38low) and other immune subsets were assessed ( $n=22-43$ /group). However the numbers at week 36 for B-cell subsets were based on only $n=2$, with all other groups $n=43-44$, and therefore caution for interpretation is required. At 120 weeks post-infusion memory B cell levels were $13.59 \%$ ( $\mathrm{n}=7$ placebo and 3 ocrelizumab cycles) and $17.73 \%$ ( $\mathrm{n}=124$ ocrelizumab cycles) of baseline levels. (B) Depletion of memory B-cells was maintained during treatment. These data were obtained from people $(n=88)$ entering the open label extension (OLE) study after the treatment free period that had received three or four 6 monthly cycles of at least $600 \mathrm{mg}$ ocrelizumab to week 72 followed by a treatment-free period to week 144, before entering the OLE phase were $600 \mathrm{mg}$ cycles of ocrelizumab was maintained at 24 week intervals. The results represent the mean \pm standard deviation of cells/ $\mu \mathrm{L}$ ( $\mathrm{n}=22-69 /$ group week 22-72). Although CD19 B-cells numbers were consistent with the original levels, the baseline memory B-cell levels failed to return to original levels at the start of the OLE. PMN = polymorphonuclear neutrophil.

\section{FIGURE 1}




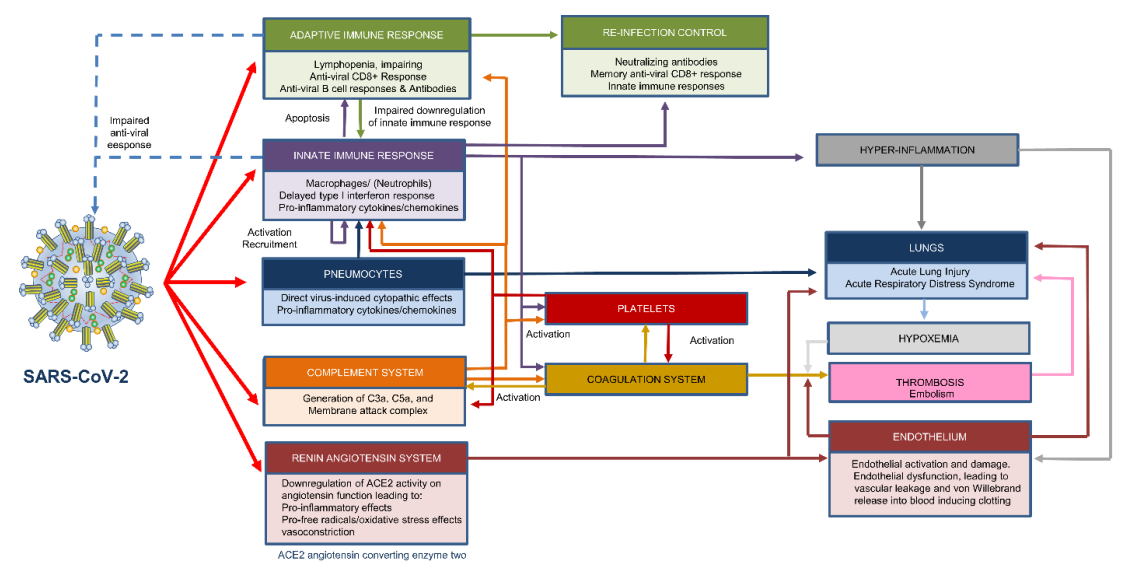

FIGURE 2. 

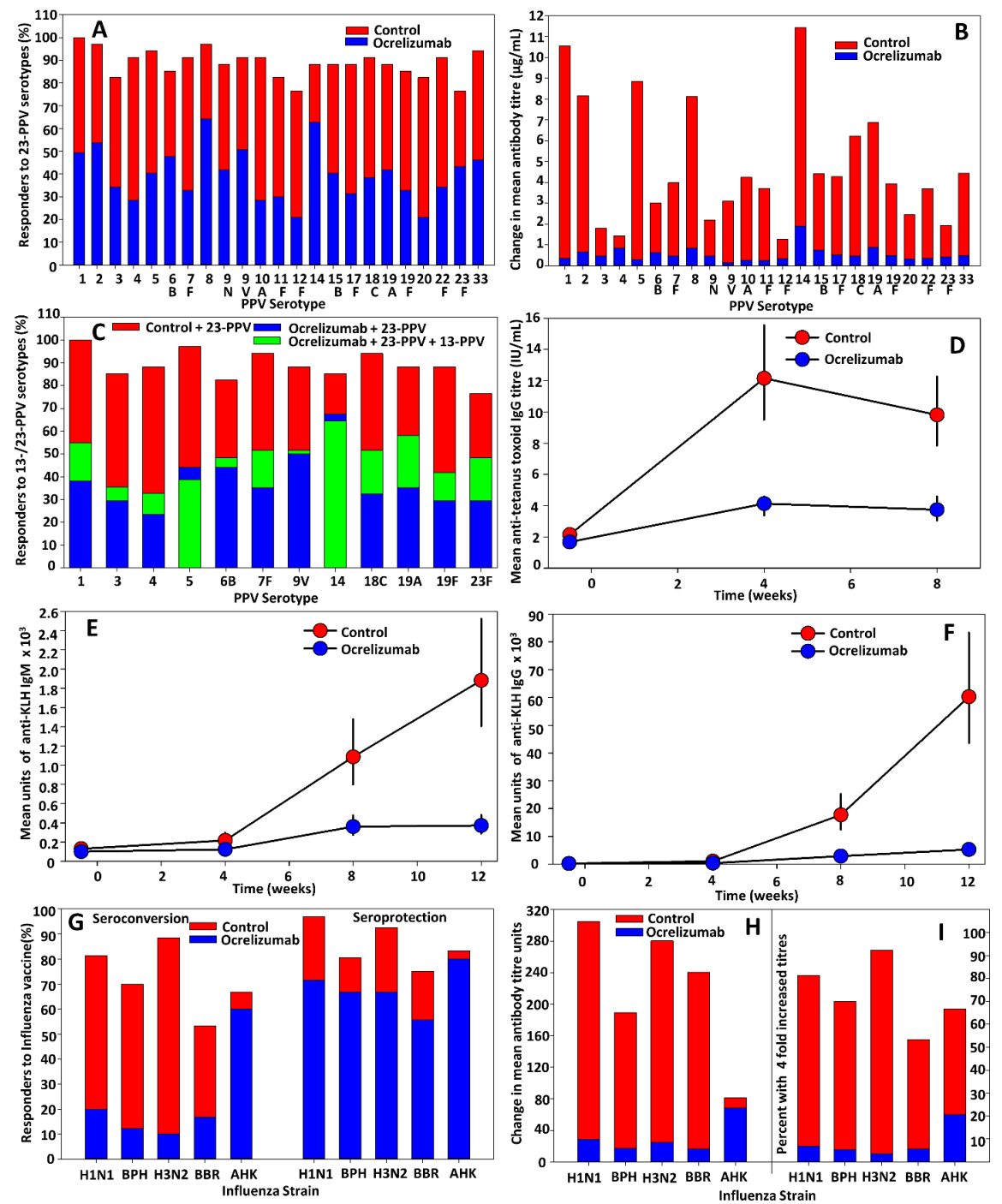

FIGURE 3
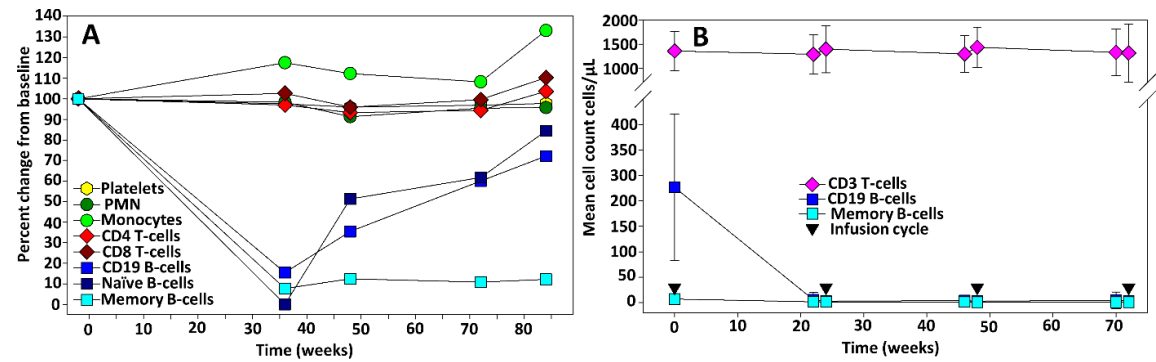

FIGURE 1 (Enlarged) 

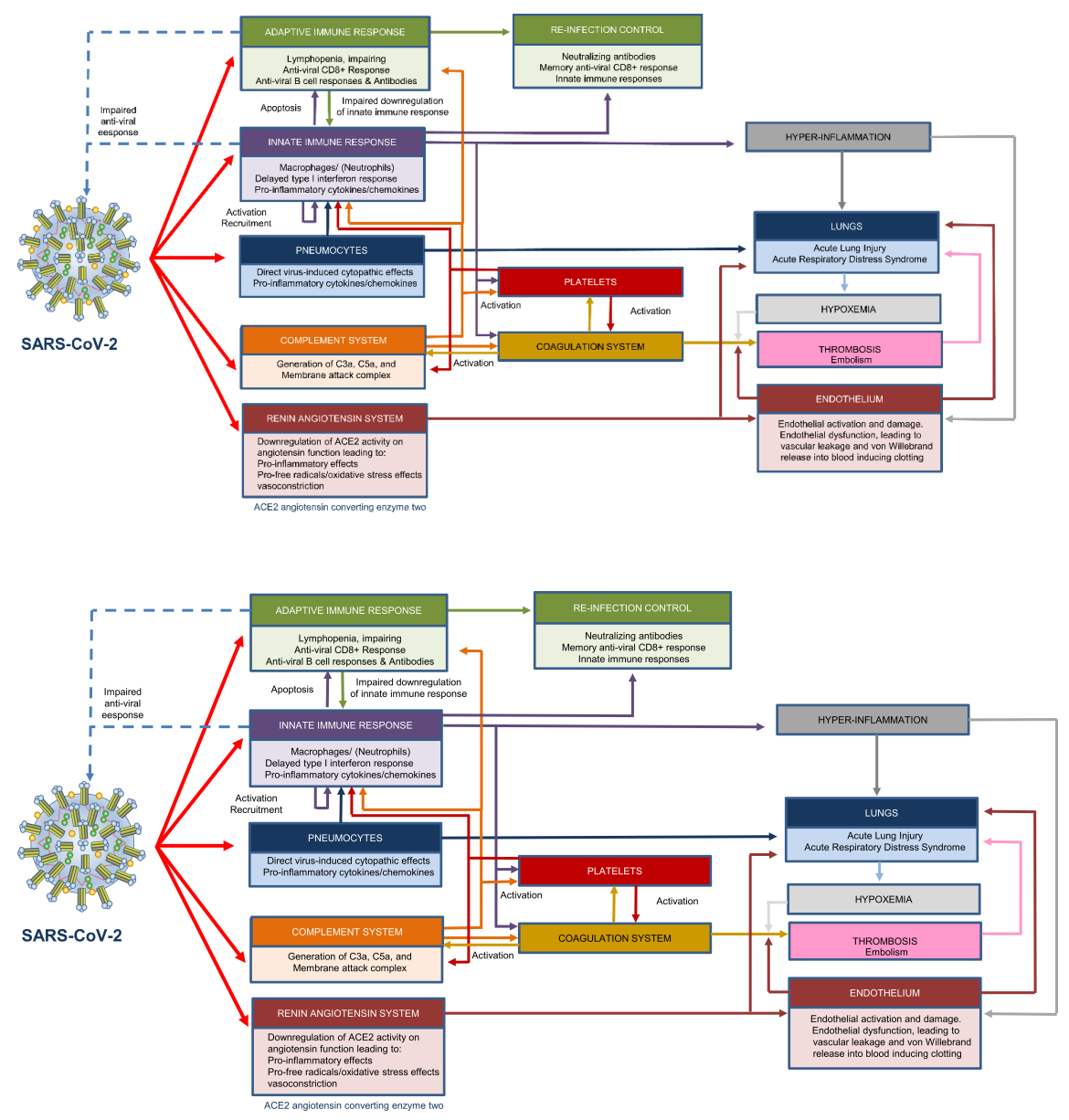

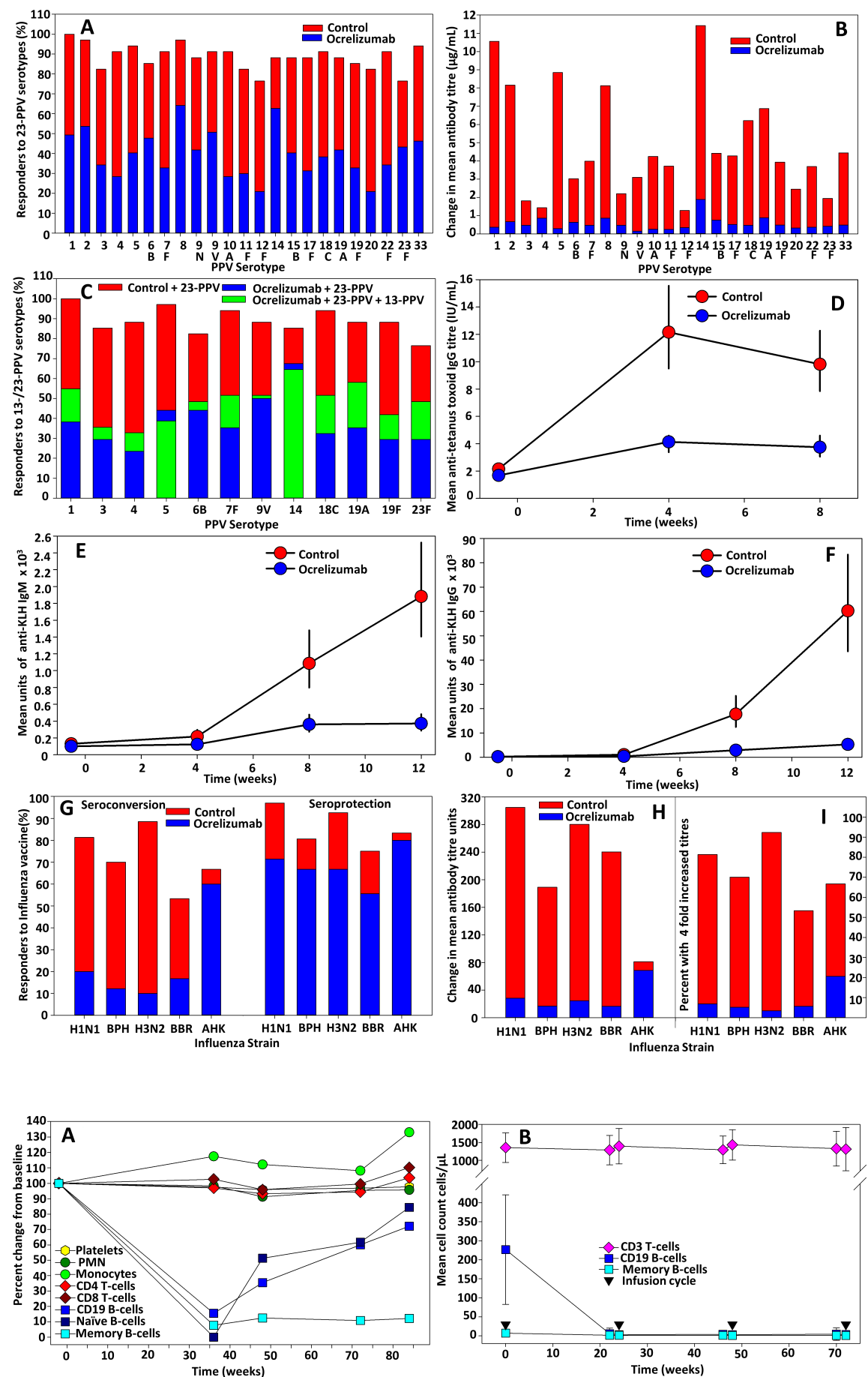